\title{
Some Important Secrets of Language Development
}

\author{
By: Muhammad Qasim Gurbaz \\ Senior Teaching Assistant, Pashto Department, Faculty of Languages and Literature, Shaikh \\ Zayed University, Khost, Afghanistan \\ E-mail: qasim.gurbaz@gmail.com
}

\begin{abstract}
:
Language is a jewel in the human body. If it is not available, no phenomenon can compensate for its absence. Every human with a language is known as a skillful person. If language is downfallen, almost all human beings' relations are damaged. Language, like all other phenomena of human culture, is closely linked to a human community, an event that occurs in a community, taking its own steps towards perfection in that community. Language is the only source of communication among the people. In fact, it is a source of reflection of the aspirations and desires of the people and a great tool for finding ways to meet their needs. In the process of research, I have clarified what language means, what it is called. As a result of the research, it has also become clear what is its value in social life, what is its importance. Language functions were also highlighted during the research. Some important factors and characteristics that lead to the development of a language are highlighted in details. If the speakers of any language take advantage of the mentioned ways to develop their language, to contrive for it to conclude all the mentioned possibilities and factors in their language, I am sure that their language will be taken place among the advanced languages.
\end{abstract}

Keywords: Language, importance of language, functions of language, ways of language development. 


\section{Introduction}

Language is a social phenomenon, emerging in society. Life, survival, sustainability and development are inextricably linked with the life, sustainability and development of a human community. Research has shown as a community is moving forward, taking steps towards development, language also does the same. It is essential for the development of a language to have equal access to all aspects of social life.

Thus the results of human intellectual activity, which are felt in various ways, become usable and useful through language, and it is also possible to understand them through language. The value of language in social life demands to contrive for its development. The more a language progresses and develops, the better it can serve nations because the more interesting the understanding of a language, the more effective it is when it is developed in the community. I have done my research writing to the best of my ability with the strength of my pen and the review of others' sources. In this article, I have covered some of the factors, characteristics and conditions that can play an important role in the process of language development.

\subsection{Research Questions}

This research article has been written for the purpose to answer the following questions:

a) What are the factors, characteristics and ways of language development?

b) To what extent do the factors, characteristics and ways will help the language to take its own rapid steps towards development?

\section{Literature Review}

Taniwal (2009) argued about the development of a language as it should be a means of learning at the community level that all office works should be done, and it should be fully integrated into the media, such as it can be used in radio, television, internet, computer and other such devices. He goes on to say that in addition to this, it is necessary to be a general means of communication and understanding in daily life and work. 
Taniwal further states that the scholars, researchers and writers of a language should be involved in writing and researching in their own language and publish their works in any field and present them to their society and people.

Words, proverbs, poems and prose of a language should be collected and separate dictionaries needs to be written in the relevant language. Valuable publications such as books, articles and so on should be translated from other languages. Current language and its values has to be translated into other languages employing all means of media such as Newspapers, Magazines, Radio, Television, Computer, Internet and so on. This has to be compared to other languages, shared traits has to be benefited and the financial development of that language speakers as Trade, industry, agriculture, exploitation of land resources, exports, etc. should be taken into consideration (Muslimdost, 2009).

In respect to the development of language, Shashai (2010) stated that speakers of the language should pay close attention to the authenticity and purity of their language, work hard in training and nurturing their original words, phrases and terms, in everyday speech and writing. Do not easily replace others' words, phrases, and idioms in conversations and writings instead of the ancient heritage of the fathers and grandfathers of their language.

Forming new terms and words is a modern language requirement and a systematic program is needed to do so. By doing so, particular theories will be suppressed, and the language will not be deprived of growth and development (Rafi, 2015).

If we have look at the above works, each scholar has shared at least some of the factors, methods and some secrets of the development of the language with readers as they could. No one of the works has not brought the mentioned methods and reasons for the development of the language in a regular, complete and systematic manner which is completely satisfactory and assurance. Noting the importance of such topic, it was necessary to further develop and expand the topic, so I decided to write a research paper under this title to the best of my ability to further develop the topic, clarify the remaining dark aspects and readers' unanswered questions may have been answered to some extent. 


\section{Language}

Linguists have shared different definitions of language with us by bringing different letters and words, using different types of sentences, there are some differences between them in terms of content, but in general, there is a basic and important unity among them since, all linguists accept that language is a great source of understanding and communication. To further clarify the issue, some linguists have defined language as;

Mahbob (2017) defined language as; language is a collection of specific contracted symbols, each symbol indicating a mental image of us, so that for each symbol we have a specific objective image in mind. These images include things of human time and environment, characteristics, accidents, phenomena, actions and the relevant speaker's own ideas, thoughts, desires, demands, goals, feelings, reactions and everything else that is in the heart and mind.

Language is a source of sharing of information (Peshawrai, 2012).

Marhoon (2017) stated the definition of language as; Language is the part of the human body that makes meaningful and meaningless sounds out of one's mouth and these voices translate human thoughts.

Language is the sounds that human beings utter in order to express their thoughts and ideas through the vocal organs under a special order and system and thus communicate with each other (Shaker, 2019).

\subsection{Importance of Language}

Language is a unique gift from Almighty God to mankind. Without the use of language, human growth cannot take place because at any time and in any place, it is accompanied with human beings through thought, brain, worship, ideas, and relationships when talking to other human beings. Language is a storehouse of knowledge and a means of thinking, a transmitter of knowledge, situations, events and information from one generation to other, a great means of establishing relationships between human beings. 
Language is what keeps the graph of the benefits of human life high because without language, a person would be in utter darkness, like an irrational animal. It is the ability of human beings to distinguish themselves from animals by combining letters and words (Niazai, 2012).

Ludin (2016) says language plays a very important role in providing jobs to the people. Language is a very important tool in regulating human activities, whether they are shared or not.

Language is a very high cultural value by which human has earned the title of the noblest of the universe. This great cultural value is a social phenomenon, emerging in community, connected to it. Lest, if it is removed from society, it loses its chance of survival. Thus, if the language of a human community is taken away, social life and the social system are destroyed. The doors of life, stability and development of a community are closed, the human community is plunged into a deep abyss and human culture is put to an end.

If there is no means of communication among the people, they will not be able to cope with the difficulties and find other ways to overcome them. If we look at the importance of language, we will see that language is the only way to get rid of rubbish and show the way. Human has charted the path of progress with the help of this tool and is witnessing great progress today. They shared their achievements and experiences and has taken advantage of them and made up for the shortcomings of their life (Taniwal, 2009).

\subsection{Language Functions}

In general, language is used for three purposes. They are as follows:

A. Language Information Function: This language function includes connection with others, information sharing, and communication.

B. Explicit Function: In this section, the speaker's thoughts, feelings, ethics, knowledge and capacity reach to the listener and in return, the same feelings are aroused in the listener, viewer or reader and the second person assumes that he/she is the first person. 
C. Instructional Function: The function of language in this section is to recommend, instruct, and request whether or not to perform an action (Mahbob, 2017).

\section{Ways of Language Development}

Ludin (2016) says language is a social phenomenon. As the community develops, knowledge and technique flourish in it, so does the language of the community develop, and linguistic units are created for many subjects.

Language is a social phenomenon. It has evolved in accordance with social life and is in its infancy according to social, political and economic conditions. These social, political and economic conditions either promote or destroy and kill the language (Hilaman, 2012).

Ishaqzai (2020) stated some tips and secretes to help develop a language which are as follow:

- It is necessary to conduct scientific and educational workshops on language development.

- International and national exhibitions should be held.

- Terminology and terms should be protected.

- The use of language in tourism, foreign and international relations should be facilitated.

- Particular attention should be paid to the role of language in national literature.

- The aspects of printing and journalism (translation, research and creation) should be strengthened.

- Beyond the development of a language, it is essential to have national and standard spelling and composition.

- Observe linguistic and ethnic movements.

- To be kept away from the threat of colonial movements.

- Religious councils: Religious councils can play a major role in the promotion and financing of language and culture because religious and theological concepts are directly related to human emotion and psychological power. 
In religious gatherings, concepts are expressed that have a profound effect on the emotional and psychological power of people and are handed down to human memory. It is a process that takes place in sacred and relatively sacred places, so if language is nurtured in places that enjoy the support and funding of the physical and spiritual power of society, then language develops gradually and abnormally.

- Music and acting: Music is also a very important element of folk culture, and its influence cannot be denied in the field of language and linguistics. Songs and music not only acquaint people with the phonemes and vocabulary of the language in public gatherings but also force people to memorize them. Representation, like an art, reflects the identity and existence of language and people, such as Attan, which is a symbol of Pashto and Pashtuns identity. In the field of acting, film, theatrical, dramatic and satirical scenarios are the major factors in the financing of language. Promoting and expanding take place among them.

Furthermore, Taniwal (2020) also stated some tips and secretes which cause development of a language they are as follow:

- Language should be a means of understanding and communicating in the community or in the context of daily life. Here a language should be given priority based on the standards of linguistics and social structure.

- Be the language of learning, education and teaching.

- It should be given the power to communicate and use in economic, political, technical and other fields.

- Pay attention to the natural structure of a language.

- Since not all languages are progressing at the same level, the process of purification should be followed in order to prevent the use of the original words of a language and archeology, but in this case, the joint condition and consensus of scholars is the main condition. The government should support the decisions of scholars in this regard. 
- Cultural aggression must be stopped on the basis of scientific principles. By doing so, the original culture and history of a society is saved from being distorted and lost.

- Illiteracy is one of the major cause of social misfortunes and suffers in the society. This point needs to be taken seriously. The government and academic centers have a great responsibility in this regard.

- It should be the official language.

Moreover, Muslimdost (2009) also explains some tips and secrets for language development as follows:

- Words, proverbs, poems, and prose of language should be collected and separate dictionaries should be written in language as well.

- It should have government patronage and enjoy political rights.

- An inclusive delegation of linguists should always be in close contact with language and language speakers and conduct their activities in the light of linguistic principles on linguistic topics as needed.

- It should be compared with other languages and take advantage of common values.

- All means of publication such as newspapers, magazines, radio, television, computer, internet and so on should be used in the dissemination of the language.

Shashai (2010) says that the native speakers of any language should pay close attention to the authenticity and purity of their language. They should work tirelessly to educate and nurture their original words, phrases and idioms, and do not easily replace obscure words, phrases and idioms in everyday speech and writing, which are the ancient heritage of their fathers and grandfathers of language speakers.

Creating new expressions and words is a modern language requirement and a systematic program is needed to do so. By doing so, it will both prevent particular ideas and as well as language from destroying (Rafi, 2015). 


\section{Research Methodology}

The research method of the article is based on library. Strong and reliable sources have been used in this research and the topics have been analyzed and discussed on the basis of scientific reasons.

\section{Results and Discussion}

The article provides accurate information to best determine the language, in this regard, the views of scholar have been included in it and analyzed and discussed according to the principles of research. Subsequently, the importance and value of language have been explored, and it has been shown that language is the highest principle of human art. For example, if a person has a beautiful body but is deprived of the blessings of language, then without a doubt, materially and spiritually very imperfect human being is known. During the research, accurate information about the functions of language is given to the readers. The main topic of the article, which is the some important secrets of language development, have been explored in the past where some articles have been published on it. For example, Taniwal has been explored the same topic but is insufficient. Also, Muslimdost has worked on the mentioned topic in his book which are the ways of language development and are a bit richer than Taniwal but still is inadequate and they are not in a position to answer many questions about it.

Shashai has given various views on the development of language, but not in a systematic way, as well as in Habibullah Rafi's work. There may be some useful results in the process of language development but not in such a way that many questions can be answered. I decided to study the subject extensively in the light of past works. Thankfully, I was able to make the most of it. Then I studied about the topic in such depth with the force of my pen and thought, in spite of extensive study, then I interpreted the issues one after the other in such a systematic way that as a result many dark aspects became clear. The article can answer a lot of questions related to the topic and the mentioned secrets can really play a vital and important role in the development of a language. 


\section{Conclusion}

In the course of my research, I came to the conclusion that I should give the readers more accurate and reliable information about the definition and identity of the language. Then I have discussed the subject of the importance of language in the light of the views of various scholars. I then analyzed the topic of the functions of language and finally explained the main topic of the article which is the some important secrets of language development, using my knowledge and other authoritative sources to answer many of the questions related to the topic.

\section{References}

Hilaman, M. Q. (2012). The completing Process of Pashto standard writing. Ghazim Press.

Ishaqzai, O. (2020). Social factors in language transformation and financing. Retrieved January 25, 2020 from mazigar.com/archives/1950.

Ludin, D. M. (2016). General linguistics issues. Jalalkoot: Eastern Literary Process.

Ludin, D. M. (2016). Language and society. Jalalkoot: Eastern Literary Process.

Mahbob, M. Sh. (2017). Pashto regularity. Jalalabad: Momand Publishing Community.

Mahbob, M. Sh. (2017). The grammar writing methodology. Jalalkoot: Eastern Publishing Community.

Marhoon, M. (2017). Historical linguistics. Kabul: Kayenat Publishing Community.

Muslimdost, A. (2009). Sweet language. (4 ${ }^{\text {th }}$ ed). Peshawar: Inayat Bookstore.

Niazai, R. (2012). Historical process of grammar writing in Pashto. Danish Publishing Community.

Peshawari, Sh.K. (2012). Pashto grammar in its own form ( $2^{\text {nd }}$ ed). Danish Publishing Community.

Rafi, H. (2015). Linguistics. Jalalabad: Momand Publishing Community. 
Academic Journal of Research and Scientific Publishing | Vol 3 | Issue 32

Publication Date: 5-12-2021 ISSN: 2706-6495

Shaker, N. A. (2019). Linguistic research $\left(2^{\text {nd }}\right.$ ed). Kandahar: Sadaqat Publishing Community.

Shashai, M. Kh. (2010). Today's issues of Pashto language. Kandahar: Allama Rashad Publishing Community.

Taniwal, M. (2009). Language and society. Language and Literature Center of the Academy of Sciences of Afghanistan, Kabul: Shoaib Press.

Taniwal, M. (2020). Essential reasons for language development. Retrieved June 20, 2020 from https://asa.gov.af/index.php/ps/zairy_journal.

Copyright (C) 2021 Muhammad Qasim Gurbaz, AJRSP. This is an Open-Access Article Distributed under the Terms of the Creative Commons Attribution License (CC BY NC)

Doi: doi.org/10.52132/Ajrsp.e.2021.32.4 